\title{
Treatment of chancroid
}

\section{A comparison of sulphamethoxazole and trimethoprim- sulphamethoxazole}

\author{
M V FAST, * H NSANZE, † F A PLUMMER,* L J D’COSTA, \& I W MACLEAN,* - \\ AND A R RONALD* \\ From the Department of Medical Microbiology, ${ }^{*}$ University of Manitoba, Canada, and +University of \\ Nairobi, Kenya; and the $¥$ Special Treatment Clinic, Nairobi, Kenya
}

SUMMARY Since sulphonamides are no longer predictably effective in the treatment of chancroid the combination of trimethoprim-sulphamethoxazole (TMP-SMX) was evaluated to identify other effective regimens. One hundred and nine patients with genital ulcers (75 men and 34 women) seen at the Special Treatment Clinic in Nairobi, Kenya, were randomly assigned to treatment with a seven day course of either sulphamethoxazole $1000 \mathrm{mg}$ twice daily or trimethoprim (160 mg)-sulphamethoxazole $(800 \mathrm{mg})$ (TMP-SMX) twice daily. Haemophilus ducreyi was isolated from the ulcer in 57 patients (33 men and 24 women). 16 patients were subsequently diagnosed serologically as having syphilis. No aetiological diagnosis was made in 40 patients. Treatment with sulphamethoxazole failed in five of $21(24 \%)$ culture positive patients who were available for evaluation after seven days, whereas all 19 of such patients who were treated with TMP-SMX responded to treatment. Of the 21 isolates available for susceptibility testing, all were susceptible to trimethoprim alone (MIC $<0.5 \mathrm{mg} / \mathrm{l}$ ) and three were resistant to sulphonamides, all three containing a 4.9 megadalton (Mdal) plasmid. Two of the three patients from whom these isolates had been obtained were treated with sulphamethoxazole and both were clinical and bacteriological failures. Five of six patients with sulphonamide-susceptible $H d u c r e y i$ responded to treatment with sulphamethoxazole. Failure of sulphonamides to eradicate $H d u c r e y i$ in some patients with chancroid is associated with the presence of a sulphonamide resistant plasmid. In regions where this plasmid is present in $H$ ducreyi TMP-SMX is the preferred treatment for chancroid.

\section{Introduction}

For more than four decades sulphonamides have been the treatment of choice for patients with chancroid. Their effectiveness against Haemophilus ducreyi has been widely reported both in vitro, ${ }^{1-3}$ and in therapeutic studies. ${ }^{4-9}$ Some patients with chancroid do not, however, respond to sulphonamide treatment and not all patients are able to tolerate sulphonamides. ${ }^{9-12}$

Several other antibiotics which have been shown to be therapeutically useful include: penicillin, ${ }^{13}$ the

Address for reprints: Professor A R Ronald, Department of Medical Microbiology, University of Manitoba, 730 William Avenue, Winnipeg, Manitoba, Canada R3E OW3

Accepted for publication 11 April 1983 aminoglycosides, ${ }^{12} 1415$ cephalothin, ${ }^{11}$ chloramphenicol, ${ }^{1316}$ and the tetracyclines. ${ }^{916}{ }^{17}$ Of these, only the tetracyclines have been widely used. In vitro resistance of $\boldsymbol{H}$ ducreyi and clinical failures have, however, been reported from several countries.9-12

In a previous study we showed that a sulphonamide-trimethoprim combination was an effective cure for chancroid. ${ }^{18}$ Numerous isolates of $\boldsymbol{H}$ ducreyi from Canada, the United States, Europe, and Africa have been tested in our laboratory and found to be susceptible in vitro to trimethoprim-sulphamethoxazole (TMP-SMX). While investigating doxycycline Stamps noted that eight tablets of TMP-SMX (equivalent to $640 \mathrm{mg}$ of trimethoprim and $3.2 \mathrm{~g}$ of sulfamethoxazole) given as a single dose of fered promise in the treatment of genital ulcer disease in Zimbabwe. ${ }^{17}$ The aetiology of these ulcers was not, however, confirmed by isolation of $\boldsymbol{H}$ ducreyi. A recent study 
from Rotterdam suggests that the combination is uniformly effective both in vivo and in vitro against $H$ ducreyi. ${ }^{19}$

On the basis of this evidence we undertook a controlled double-blind study to compare the efficacy of sulphamethoxazole and a combination of trimethoprim-sulphamethoxazole.

\section{Patients and methods}

\section{STUDY POPULATION}

Patients enrolled in the study included 33 men who sought treatment at the Nairobi Special Treatment Clinic from December 1980 to January 1981, and 24 women seen between February and September 1981 . Informed verbal consent and standard history were obtained and a physical examination performed at the initial visit by one of us. No patient had a history of drug allergies. Patients who had received antimicrobial agents within a week before being seen and pregnant women were excluded from the study.

\section{LABORATORY STUDIES}

Laboratory techniques to identify $H$ ducreyi in this clinic population have been described previously. ${ }^{20}$ Briefly, for isolation of $\boldsymbol{H}$ ducreyi material from the ulcer base was cultured on enriched chocolate agar with vancomycin $3 \mathrm{~g} / 1$ and $5 \%$ fetal calf serum (ECAVS), incubated at $35^{\circ} \mathrm{C} \pm 1^{\circ} \mathrm{C}$ in a candle jar in a moist atmosphere for $\mathbf{4 8}$ hours and then checked for growth daily for one week. Identification of $\boldsymbol{H}$ ducreyi was based on typical colonial morphology, Gram stain, and nutritional requirements. ${ }^{21}$ Fluctuant buboes were aspirated and cultured in a similar manner.

Ulcer scrapings were also cultured for herpes simplex virus ${ }^{20}$ and dark field microscopy was carried out on all ulcers. Serum from each patient was also tested for syphilis by rapid plasma reagin (RPR) and Treponema pallidum haemagglutination (TPHA) tests.

Minimum inhibitory concentrations (MICs) were determined as follows: individual isolates of $\boldsymbol{H}$ ducreyi were grown on ECAVS for 24-36 hours and a suspension of organisms of approximately $10^{8}$ colony forming units $(\mathrm{cfu}) / \mathrm{ml}$ was made. The suspension was diluted further to give a final concentration of $10^{6} \mathrm{cfu} / \mathrm{ml}$. A Steares replicator was then used to inoculate plates which contained Mueller-Hinton agar with $5 \%$ lysed horse blood, $0 \cdot 1 \%$ glucose, $0.01 \%$ glutamine, and $0.025 \%$ cysteine, to which was added appropriate dilutions of the antimicrobial agent being tested. The final concentrations of sulphamethoxazole ranged from $0 \cdot 125$ to $512 \mathrm{mg} / \mathrm{l}$, of trimethoprim from 0.015 to $32 \mathrm{mg} / \mathrm{l}$, and of TMPSMX from 0.0015 and 0.03 to 0.4 and $8.0 \mathrm{mg} / \mathrm{l}$.
Plates were read at $\mathbf{4 8}$ hours and the MIC was taken to be the dilution that showed an $80 \%$ decrease in growth compared with that of the control plate.

Plasmid analysis was carried out according to the methods of Albritton et al. ${ }^{22}$

\section{FOLLOW UP}

All patients were requested to return after $2,7,10$, 14 , and 28 days. At each visit the patient's subjective response to treatment was ascertained and lesions were re-examined for clinical response to treatment. All unhealed ulcers were recultured for $\boldsymbol{H}$ ducreyi. Serology tests were repeated on days 7 and 28.

\section{TREATMENT}

Patients were randomly assigned in a double-blind fashion to receive for seven days either sulphamethoxazole $1000 \mathrm{mg}$ by mouth twice daily or TMP-SMX, $160 \mathrm{mg}$ trimethroprim and $800 \mathrm{mg}$ sulphamethoxazole, by mouth twice daily. If the ulcer was showing evidence of healing on day 7 no further medication was prescribed and the patient was requested to return for follow up. If the ulcer had failed clinically, bacteriologically, or both to respond by day 7 the patient was given the alternative drug regimen.

\section{Results}

Enrolled in the study were 109 patients (75 men and 34 women) whose ages ranged from 15 to 40 years. $H$ ducreyi was isolated from the ulcer in $57(52 \%)$ cases and these patients (33 men and 24 women) form the basis for the evaluation of treatment. In 16 patients ulcers were diagnosed as being due to syphilis either on the basis of a positive dark field examination (five) or positive serology results, that is to the TPHA test and to the RPR test in a dilution of $\geqslant 1 / 2$. These patients are not considered further in this study, except for four (three of whom were men) who had evidence of both $T$ pallidum and $H$ ducreyi infection. Neisseria gonorrhoeae was the only pathogen isolated from two patients and these together with the $38(31 \%)$ patients in whom no aetiological diagnosis could be made are evaluated separately, although it is probable that the ulcers in some of the patients were due to $\boldsymbol{H}$ ducreyi.

Of the 57 patients with diagnoses of chancroid, 29 initially received sulphamethoxazole and 28 TMPSMX. Table I outlines their response to treatment. The lesions of all 19 patients treated with TMP-SMX and returning for follow up had resolved or were improving by day seven. Of those treated with sulphamethoxazole, the lesions of 16 of $21(76 \%)$ patients had resolved or were improving. All five remaining patients were clinical and bacteriological failures and were retreated with a course of TMPSMX and later cured. 
TABLE I Response to treatment with either sulphamethoxazole or trimethoprim-sulphamethoxazole (TMP-SMX) in patients with chancroid

\begin{tabular}{lllll}
\hline Treatment drug & $\begin{array}{l}\text { No of patients } \\
\text { (women/men) }\end{array}$ & $\begin{array}{l}\text { No seen on } \\
\text { day } 7 \\
\text { (women/men) }\end{array}$ & $\begin{array}{l}\text { No cured } \\
\text { (women/men) }\end{array}$ & $\begin{array}{l}\text { No improved } \\
\text { (women/men) } \\
\text { failures } \\
\text { (women/men) }\end{array}$ \\
\hline Sulphamethoxazole & $29(13 / 16)$ & $21(12 / 9)$ & $6(5 / 1)$ & $10(5 / 5)$ \\
Trimethoprim-sulphamethoxazole & $28(11 / 17)$ & $19(8 / 11)$ & $6(3 / 3)$ & $13(5 / 8)$ \\
& $57(24 / 33)$ & $40(20 / 20)$ & $12(8 / 4)$ & $23(10 / 13)$ \\
\hline
\end{tabular}

*All were culture positive on day seven.

The time to healing - that is the time from the start of treatment to complete ulcer resolution-is shown in the figure. The ulcers in women generally appeared to heal more quickly than those in men.

Twenty one of the isolates were available for susceptibility testing. All were susceptible to trimethoprim with MICs of $\leqslant 0.5 \mathrm{mg} / \mathrm{l}$; three strains were resistant to sulphonamides with MICs of $>512 \mathrm{mg} / \mathrm{l}$ (table II). The three sulphonamide-resistant isolates carried a 4.9 Mdal plasmid which codes for sulphonamide resistance. The two patients with sulphonamide resistant $\boldsymbol{H}$ ducreyi, who were treated with sulphamethoxazole, failed to respond clinically or bacteriologically and required alternative treatment. The lesion of a fourth patient from whose ulcer no organisms were isolated, healed within seven days of sulphamethoxazole treatment. She had a persistent draining bubo, however, from which $H$ ducreyi containing the sulphonamide resistant plasmid was isolated. The organism, however, never grew well enough for susceptibility testing. The bubo eventually resolved with erythromycin treatment. Five of six patients with sulphonamide sensitive $H$ ducreyi responded to treatment with sulphamethoxazole, and one, who was a treatment failure, responded to the alternative regimen.

Of the $\mathbf{4 0}$ patients in whom a diagnosis of chancroid, syphilis, or herpes could not be established, 19 were treated with sulphamethoxazole and 21 with TMP-SMX (table III). Of those treated with sulphamethoxazole the lesions of $41 \%$ resolved and $59 \%$ improved by day seven: of those treated with

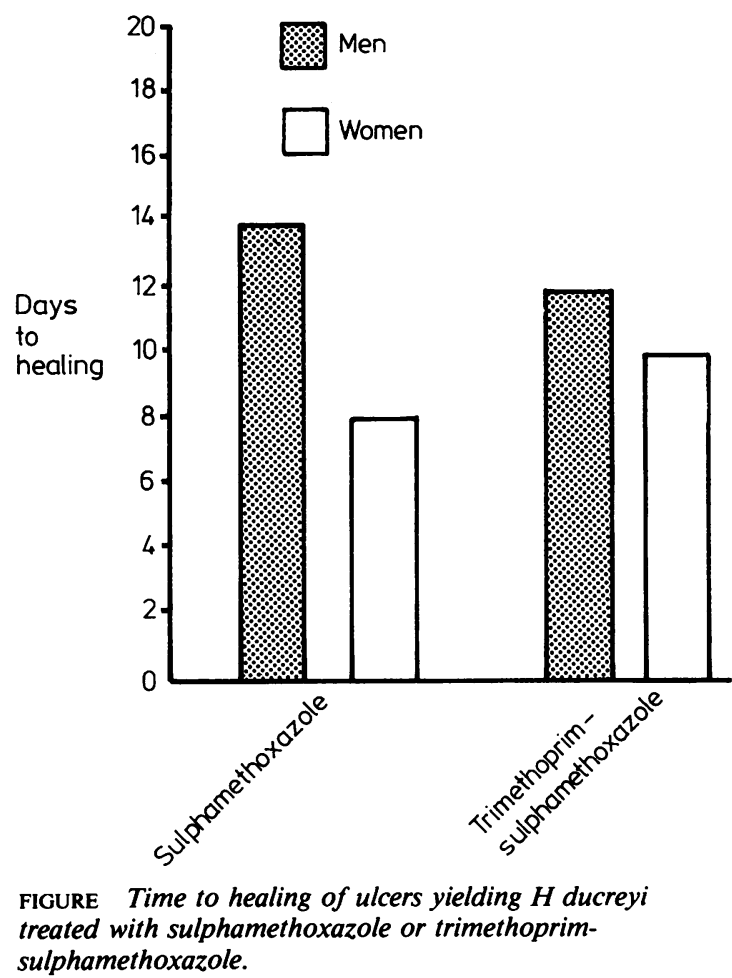

TMP-SMX the lesions of $61 \%$ had resolved and $39 \%$ were improving by day seven. There were no treatment failures in this group of patients. Of the 31

TABLE II Minimum inhibitory concentrations (MICS) of sulphamethoxazole and trimethoprim inhibiting growth of 21 isolates of $\boldsymbol{H}$ ducreyi*

\begin{tabular}{lllllllllllllll}
\hline & $M I C S$ & & & & & & & & & \\
& 0.06 & $0 \cdot 12$ & 0.25 & 0.5 & $1 \cdot 0$ & $2 \cdot 0$ & $4 \cdot 0$ & $8 \cdot 0$ & 16 & 32 & 64 & 128 & 256 & 512 \\
\hline $\begin{array}{l}\text { No of strains inhibited by sulphamethoxazole } \\
\text { No of strains inhibited by trimethoprim }\end{array}$ & 3 & 14 & 1 & 2 & 4 & 10 & & & & & & & $3+$ \\
\hline
\end{tabular}

*Concentrations of TMP-SMX of $\leq \frac{0.025}{0.5}$ inhibited all strains except those containing the $4.9 \mathrm{Mdal}$ plasmid, which required concentrations of $\frac{0 \cdot 1}{2 \cdot 0}$ or $\frac{0 \cdot 2}{4 \cdot 0}$ for inhibition.

†No of strains from which a $4.9 \mathrm{Mdal}$ plasmid was isolated. 
TABLE III Response on day seven to treatment with either sulphamethoxazole or trimethoprim-sulphamethoxazole in patients with no aetiological diagnosis

\begin{tabular}{lllrr}
\hline Drug regimen & $\begin{array}{l}\text { No of } \\
\text { patients }\end{array}$ & $\begin{array}{l}\text { No seen on } \\
\text { day seven }\end{array}$ & No cured & $\begin{array}{l}\text { Treatment } \\
\text { failures }\end{array}$ \\
\hline Sulphamethoxazole & 19 & 17 & 7 & 10 \\
Trimethoprim-sulphamethoxazole & 21 & 18 & 11 & 10 \\
& 40 & 35 & 18 & 17 \\
\hline
\end{tabular}

patients in this group in whom the time to healing could be evaluated the average time for those treated with sulphamethoxazole was 10 days and 11 days for those treated with TMP-SMX.

Half of both men and women with genital ulcers in this study had accompanying inguinal adenopathy defined as a lymph node enlarged to $>1 \mathrm{~cm}$ in diameter. Healing of the smaller buboes $(<5 \mathrm{~cm})$ paralleled ulcer healing and often resolved more quickly than the ulcers. Large buboes $(>5 \mathrm{~cm})$ almost invariably resolved more slowly than did the ulcers.

\section{Discussion}

It would appear that, except in patients with sulphonamide resistant $\boldsymbol{H}$ ducreyi infection, sulphonamides are still the effective treatment for chancroid. Unfortunately, it is impossible to know at the outset whether the organisms are susceptible or resistant to sulphonamides. In addition, MIC determinations and plasmid analysis are obviously impractical in most areas where chancroid is endemic. Alternative regimens are therefore needed for chancroid treatment, despite the established usefulness of sulphonamides.

The tetracyclines possess no advantage except in patients infected with $H$ ducreyi resistant to sulphonamide and susceptible to tetracycline; chloramphenicol is obviously a drug to be kept in reserve for more life-threatening infections; aminoglycosides and cephalosporins used to date must be given parenterally for several days, and this is not practical or economically feasible in areas where chancroid is common. In this study all patients responded to the combination of trimethoprim-sulphamethoxazole and all isolates tested were susceptible in vitro to this drug. In the proved cases of chancroid TMP-SMX was preferable to sulphamethoxazole alone although in the cases of doubtful aetiology both drugs appeared to be effective. It would appear that a trimethoprim-sulphonamide combination should become the alternative treatment of choice in regions where sulphonamide resistant $H$ ducreyi is widely prevalent.

Determining antimicrobial susceptibilities of fastidious haemin-requiring organisms like $H$ ducreyi is difficult. The primary problem is that of the culture medium, as media that support the growth of $H$ ducreyi cannot necessarily be used for susceptibility testing. We and other investigators have had particular difficulties with sulphonamide and trimethoprim susceptibility testing. Most media that support growth of $\boldsymbol{H}$ ducreyi contain thymidine, which antagonises the antibacterial activity of trimethoprim, and para-aminobenzoic acid (PABA), which competes with the sulphonamides. The medium used in this study appeared to overcome this problem with horse blood providing haemin (haemoglobin) and thymidine phosphorylase, as we knew from previous studies that glucose, glutamine, and cysteine and a source of haemin are necessary for the growth of $H$ ducreyi. Because the organisms are fastidious, however, about one quarter of all isolates would not grow on our susceptibility medium.

The correlation between results of antimicrobial susceptibility testing and clinical and bacteriological response to treatment suggests that the method is valid. Three strains of $\boldsymbol{H}$ ducreyi with MICs greater than $512 \mathrm{mg} / \mathrm{l}$ of sulphamethoxazole contained the 4.9 Mdal sulphonamide resistant plasmid and sulphamethoxazole was ineffective in the treatment of these patients. In addition, the MICs of the combination of TMP-SMX were higher in these patients than in patients with sulphonamide susceptible isolates of $\boldsymbol{H}$ ducreyi. Fortunately, all isolates were uniformly susceptible to TMP. Strains which lacked the sulphonamide resistant plasmid had uniformly low MICs $(\leqslant 2.0 \mathrm{mg} / \mathrm{l})$ to sulphamethoxazole and, with one exception, patients with these organisms responded well to treatment with this drug. There is no obvious explanation for the one treatment failure in a man infected with a sulphonamide susceptible organism. His ulcer was severe as were many others and we have no evidence of poor compliance.

The woman whose culture negative ulcer responded to sulphamethoxazole treatment, but whose bubo persisted and from which was isolated $H$ ducreyi containing the 4.9 Mdal plasmid, poses some interesting questions. Was she infected with two strains of $\boldsymbol{H}$ ducreyi? Did an originally susceptible organism acquire a resistant plasmid during the period of infection?

We were surprised that ulcers in women healed more quickly than those in men. It did not appear 
that women sought treatment when ulcers were less severe or of shorter duration. Although the mean time to healing of ulcers in men treated with sulphamethoxazole appeared longer than for those treated with TMP-SMX, with one exception the ulcers in patients with proved sulphonamide susceptible $\boldsymbol{H}$ ducreyi who were treated with sulphamethoxazole resolved in $\mathbf{1 0}$ days. Both drugs were equally effective in women.

Several questions require further investigation. Is trimethoprim alone as effective as the combination, particularly in patients with sulphonamide resistant $H$ ducreyi infections? What is the optimum duration of treatment? Although the Centers for Disease Control recommend that treatment should be continued for a minimum of $\mathbf{1 0}$ days and until ulcers, lymph nodes, or both have healed, there is no evidence that shorter regimens may not be equally effective. In all patients with $\boldsymbol{H}$ ducreyi infections in this study who were ultimately cured without further treatment, the ulcer was culture negative on day three and remained culture negative even in patients in whom time to healing was prolonged. Would shorter treatment time be equally effective in eradicating $H$ ducreyi and curing clinical chancroid?

The level of trimethoprim in the combination required to prevent growth was identical to the MIC of trimethoprim alone for the three plasmid containing sulphonamide resistant isolates. In other words, there was no evidence of synergy for these strains. In contrast, for sulphonamide susceptible strains of $H$ ducreyi the MIC of trimethoprim or sulphamethoxazole was either two, four, or eight times greater alone than when combined. True synergy was apparent for most strains. The clinical importance of this antibacterial synergy requires further study.

M V Fast received support from the Sidney Israels Fellowship. F A Plummer was the recipient of a research fellowship from the Medical Research Council of Canada. The work was supported by grants from the Medical Research Council of Canada (MA-6368), the World Health Organisation, the Canadian International Development Agency, and Hoffmann-La Roche Limited.

\section{References}

1. Mortara F, Saito MT. Sensitivity of Hemophilis ducreyi to antibiotic and other substances in vitro. American Journal of Syphilis, Gonorrhea, and Venereal Diseases 1946; 30:352-60.

2. Reymann F. Sensitivity of Hemophilus ducreyi to penicillin, streptomycin and sulfathiazole. Acta Pathol Microbiol Scand 1949;26:309-18.

3. Hammond GW, Lian C-J, Wilt JC, Ronald AR. Antimicrobial susceptibility of Hemophilus ducreyi. Antimicrob Agents Chemother 1978; 13:608-12.

4. Hanschell HM. Sulphanilamide in the treatment of chancroid. Lancet 1983; i: 886-8.

5. Culp OS. Treatment of chancroid with sulfanilamide. American Journal of Syphilis, Gonorrhea, and Venereal Diseases 1940;24:622-31.

6. Combes FC, Canizares O, Landy S. Treatment of chancroid with sulfathiazole. Investigation of the minimal effective dose. American Journal of Syphilis, Gonorrhea, and Venereal Diseases 1943;27:700-2.

7. Satulsky EM. Management of chancroid in a tropical theatre. Report of 1555 cases. JAMA 1945; 127:259-63.

8. Harp VC. Observations on chancroid therapy with and without sulfathiazole. American Journal of Syphilis, Gonorrhea, and Venereal Diseases 1946; 30:361-7.

9. Hammond GW, Slutchuk M, Lian C-J, Wilt JC, Ronald AR. The treatment of chancroid. Comparison of one week of sulphisoxazole with single dose doxycycline. J Antimicrob Chemother 1979;5:261-5.

10. Kerber RE, Rowe CE, Gilbert KK. Treatment of chancroid. A comparison of tetracycline and sulfisoxazole. Arch Dermatol 1969; 100:604-7.

11. Storey G. Clinical manifestations of chancroid. Br J Urol 1970; 42:738.

12. Marmar JL. The management of resistant chancroid in Vietnam. J Urol 1972;107:807-8.

13. Willcox RR. The treatment of chancroid. Br J Clin Pract 1963; 17:455-60.

14. Taggart SR, Hirsch H, Hendricks FD, Gable GR, Puzak MA, Greaves AB. The treatment of chancroid with streptomycin. American Journal of Syphilis, Gonorrhea, and Venereal Diseases 1949;33:180.

15. Luders G, Braun J, Pietzcker F, Schule D. Neue therapeutische gesichtspunke beim ulcus molle. Hautarzt 1975;26:35-40.

16. Asin J. Chancroid. A report of 1402 cases. American Journal of Syphilis, Gonorrhea, and Venereal Diseases 1963;36:483-7.

17. Stamps TJ. Experience with doxycycline (vibramicin) in the treatment of chancroid. J Trop Med Hyg 1974;77:55-60.

18. Fast MV, Nsanze H, D'Costa L, Karasira P, Maclean I, Ronald A. Antimicrobial therapy of chancroid: An evaluation of five treatment regimens correlated with in vitro sensitivity. Sex Transm Dis 1983; 10: 1-6.

19. Nayyar KC, Stolz E, Michel MF. Rising evidence of chancroid in Rotterdam. Epidemiological, clinical, diagnostic, and therapeutic aspects. Br J Vener Dis 1979; 55:439-41.

20. Nsanze H, Fast M, D'Costa LJ, Tukei P, Curran J, Ronald AR. Genital ulcers in Kenya: A clinical and laboratory study of 97 patients. Br J Vener Dis 1981;57:378-81.

21. Hammond GW, Lian C-J, Wilt JC, Albritton WL, Ronald AR. Determination of the hemin requirements of Hemophilus ducreyi: Evaluation of the porphyrin test and media used in satellite growth test. J Clin Microbiol 1978; 7:243-6.

22. Albritton W, Brunton JL, Slaney L, Maclean I. Plasmid mediated sulfonamide resistance in Hemophilus ducreyi. Antimicrob Agents Chemother 1982; 21:159-65. 